\title{
Cloud Computing in Supply Chain Management and Economic, Environmental and Social Impact Analysis
}

\author{
Elena PUICĂ \\ Economic Informatics Doctoral School, \\ The Bucharest University of Economic Studies, Bucharest, Romania \\ elenaa.puica@gmail.com
}

\begin{abstract}
Information and communication technology (ICT) has gained influence in supply chain management (SCM) in recent years. Supply chain management acts on operational processes, divergent and consolidated information flows and interaction processes with a variety of business partners. Considering all the well-known problems of these central information systems, the question arises whether cloud-based information systems are a better alternative to establish technological support for supply chain management and whether the effects from an economic, social and economic point of view. and environmental results have a positive impact. The aim of this research is to provide a better understanding of the overlap of supply chain management and cloud technology from an economic, environmental and social perspective.
\end{abstract}

Keywords: Cloud Computing, SCM, Economic environment, Social impact.

DOI: $10.24818 /$ issn14531305/24.4.2020.04

1 Introduction

Supply chain management (SCM) has benefited from a wide variety of technological transformations, which is different today compared to a few decades ago. Technology has had an effect on increasing profitability and efficiency for most parts of a supply chain, being a sequence or network of different companies or individuals that produce, handle or distribute specific goods or products. Technologies can provide a competitive advantage for supply chains. SCM is the streamlining of processes to the flow of goods from its conversion from raw material to final products, [1] which is applied within the organization to manage the flow of goods and services, which includes the storage of raw materials and inventory progress. [2] SCM is the essential part for every organization, whether it is small or large. [3] There are various activities in the supply chain from product development, logistics, procurement, production, as well as an information system that is needed to organize these activities. The activities of the SCM for the design, execution, control, monitoring and planning of supply chain processes lead to the creation of new values, the construction of a competitive infrastructure, as well as the synchronization of supply with demand. [4]
The use of Cloud technology in SCM offers advantages, from cost efficiency, simplicity, flexibility and scalability of the system, to real-time visibility of flows / operations. On the other hand, the use of Cloud technology in supply chain management involves some challenges regarding uncertain data security, the possibility of system failure or poor internet connection. It is important that cloud technology providers work to mitigate the disadvantages of the cloud, for example, by providing customized options or strengthening system protection. A challenge is the transition from traditional systems and methods of operation to modern practices, adopting concepts that involve the exchange of information in real time, as well as collaboration with all stakeholders in the supply chain.

It is important that the use of Cloud technology in SCM also considers the economic, environmental and social impact for many organizations, the management of these factors being a key challenge. As globalization expands, it is becoming more difficult for organizations to maintain adequate relationships with suppliers to balance economic, environmental and social performance initiatives. 
This study examines and highlights the elements that result from the use of cloud computing technology in SCM and can help companies be aware of their existence to maintain adequate collaboration in the supply chain and balance both economic and environmental performance. as well as social ones.

Therefore, this paper is presented as follows, the first part presents the theoretical basis for the constructions of the research study on Information and Communication Technology (ICT) in supply chain management, further emphasis is focused on Cloud Computing technology in supply chain management. In the last part, the study focuses on the economic, environmental and social impact resulting from the use of Cloud technology in the supply chain. Finally, the conclusions of the study are presented.

\section{Information and Communication Tech- nology in Supply Chain Management}

Information and communication technology is mainly used in supply chain management, order placement, inventory management, shipment tracking, exchange of information / transactions with suppliers, exchange of electronic payment information with suppliers, mobile connectivity and cloud-based services [5]. ICT can achieve the economic, social and environmental pillars of sustainability [6], [7] [8]. ICT is not automatically favorable, some of the unfavorable effects may be the need for materials and energy, stimulating the consumption of other resources or limiting the lifespan of other resources. [9] In order to ensure the long-term existence of a firm, it is essential to develop resilient supply chains. [8] It is controversial whether ICT appears as a threat or a remedy for a better economic, environmental and social impact. [11] In general, the link between IT and economic, environmental and social impact has two paths: information technology can become more sustainable or the use of information technology can lead to a better economic, environmental and social impact. [12]

ICT in supply chain management is not only a tool used for better communication, but also allows a company to achieve better performance and a competitive advantage. [13] ICT has a generally positive effect on SCM and performance. [14] There is also little knowledge about the overall impact of ICT on SCM, even contemporary firms are inspired by ICT and consider the adoption of new technologies as an opportunity to support the company's operations and supply chain management. [15]

As technologies develop rapidly and supply chains become increasingly complex, with a high risk of disruption, [16] it is most likely that the need for knowledge about the effects of ICTs on the economic outlook, social and environmental supply should be sought, as the importance of the SCM will increase in the near future. Although the development of supply chain management began almost two decades ago, the concept of supply chain management is still very broad and is mainly due to the lack of similarities between the definitions that different authors have attributed to this concept. [17] ICT is now associated with global productivity and communication and is of great significance in most businesses, helping them to maintain their competitive advantage. [18]

The economic, environmental and social impact in supply chains is a current field of research that has shifted from the periphery to general research in the last two decades. [19] The role of supply chains in promoting the corporate sustainability agenda is essential, given its position and ability to influence the external environment through procurement. [20]

Institutional theory suggests that business practices and organizational behavior are influenced by institutional structures that are affected by political, social, economic, and cultural forces. [21] Institutional theory aims to explain the inherent regulatory, social and cultural factors in different industries that impose inflexibility on how organizations respond strategically to external pressures. [22] Organizations will be inclined to behave and act in a socially responsible manner in a context where regulatory compliance is applicable. 
[23] Macroeconomic contexts can have a direct influence on the ideologies adopted by organizations and have encouraged the need to recognize the connection and interdependence that may exist, given that the political context could have an economic impact, social, environmental and legal implications. [24]

The role of ICT in the supply chain can improve the relationship between supply, retailers and the company. It can be said that the role of ICT has transformed the traditional supply chain through its ability to share data, exchange information, process information in real time to improve communication between external supply chain participants and members of the organization. Customization can be said to help integrate planning activities into supply chain management operations. [25] ICT plays a major role in improving the retail organization's capacity to obtain, process and exchange transactional information, which has led to improved cooperation, coordination and communication in the conduct of supply chain business operations. to production units, to distribution centers, to wholesalers / retailers, to customers. [26]

Supply chain management ICT is a concept that involves the exchange of information between stakeholders in the retail industry chain, ie retail, manufacturer and distributor, in order to achieve high efficiency and also to reduce cost. products sold by reducing delivery times and the cost of stock, as well as improving the quality of products to be delivered. [27] The adoption of ICT is spreading rapidly in supply chain management. [28] The exchange of information in supply chain management between stakeholders has become the desired aspect of managing a supply chain of a supermarket, while electronic means of information exchange are the key component to sustain the competitive advantage in the industry. . [29] Store supply chain partners, ie retailers, manufacturers and distributors, have entered a promising and challenging period in their relationships as they realize the importance of working closely together to achieve improved operational efficiency and standards. of services. [30] The current literature describes the effects of ICT as improvements in the areas of supply chain with reduced production instability, optimal inventory levels, less expensive logistics and simplified procurement systems. [31]

ICT solutions contribute to improving the level of efficiency in the supply chain process and transforms traditional supply chain management into a modern one, which is flexible and offers reliable information exchange and real-time information exchange. It can be said that the use of cloud computing, mobile and wireless technologies has brought improvements in accuracy, efficiency and transparency in supply chain management. [32]

\section{Cloud Computing in SCM}

Cloud technology has become a powerful work tool for SCM by sharing resources in real time, providing several different services, storing and accessing applications. It can help SCM grow, save costs, while creating a competitive environment with more job opportunities. [33] Cloud computing is a technology with the potential to generate substantial productivity by changing the cost structure of companies, simplifying the creation of new businesses, reducing working hours and encouraging the creation of new working methods. Cloud computing allows users to access on-demand shared configurable computing resources hosted by third parties on the Internet, instead of building their own IT infrastructure. An enterprise that migrates its IT system and data to cloud computing can store the necessary resources as needed, instead of using its own infrastructure, can reduce server and storage costs, software maintenance costs, network and energy costs. and the costs associated with disaster recovery. [34] [35] Generally operating on a pay-as-you-go basis, giving the user the option to pay for what he uses. [36]

Cloud-based platforms improve service levels by coordinating supply chain network partners (retailers, suppliers and distributors). These platforms can collect data via the Internet, perform basic analyzes and execute more accurate statistical forecasts of demand for all participants in the supply chain. For the procurement, receipt and inspection of materials 
received with the procurement processes and selection of appropriate suppliers [37] cloudbased platforms can function as a database, which contains more data about different vendors. Companies can select their suppliers according to personalized criteria in accordance with the specifications of the final product and compliance with deadlines. Cloud-based tools allow companies and suppliers to develop contracts, developing contract management.

Cloud computing provides logistics tracking operations to multiple supply chain partners for inventory, warehouse and transportation management. Processes such as supply planning, order processing, inventory management, transportation route planning can migrate to the cloud. Cloud technology can be integrated with RFID (Radio-Frequency Identification) technology allowing the tracking of inventory location and then the transmission of this information to a cloud application. The inventory path can be visible to all partners in the supply chain, from manufacturer to customer and vice versa. [38]

The two largest players providing technology solutions in SCM are SAP SE and Oracle. [39] SAP's IoT and Digital Supply Chain offer promises customers that it will help them digitize their supply chains, as well as facilitate collaboration with supply chain partners. This is done in part through cloud-based deployment. Oracle provides software as a service, as well as platform, infrastructure and data services. Oracle helps companies modernize their SCM processes by providing customers with services such as product lifecycle management, supply chain planning and order management.

To emphasize the importance of social, economic, and environmental performance, SAP SE has created cause-and-effect chains that show specific actions that lead to behavior change. Because behavior has an impact on economic and financial consequences. To understand what environmental, social, and governance issues are key priorities, SAP completed a materiality assessment to highlight those topics that contribute most to value creation.

Cloud technology has been growing rapidly in the last four years in terms of its use in supply chain management. Overall, comparing the four years 2016 and 2020, the utilization rate of Cloud technology is increasing, with a percentage of $31.11 \%$ (see Figure 1).

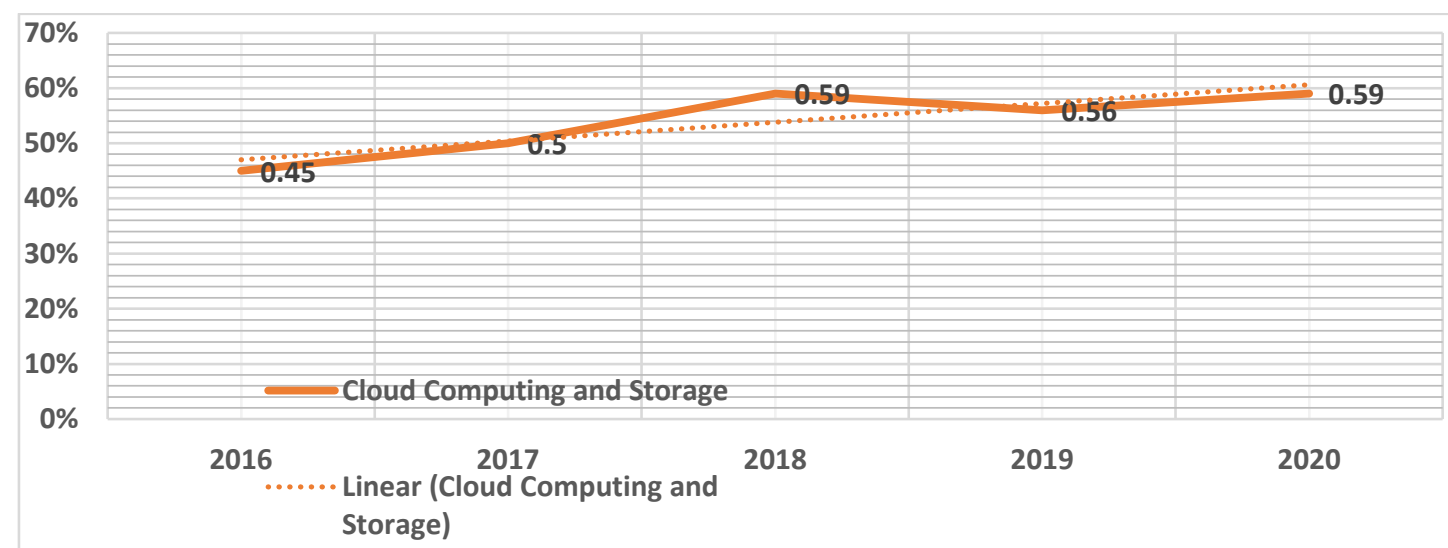

Fig. 1. The level of use of Cloud technology in the last four years in Supply Chain Management (2016 - 2020)

Source: Own processing based on data provided by MHI Annual Industry Report

Cloud computing allows remote access to servers, storage, databases and Internet application services for users around the world. These web-based IT resources are available to users in a flexible and low-cost way. Cloud
Computing allows small and small companies to use these resources in the cloud, saving the cost of the initial investment needed to build an IT structure from scratch. Through rapid 
prototyping and collaborative design and improved manufacturing processes, Cloud can make a significant contribution to supply chain coordination. Technology can underpin interactive and collaborative learning (World Economic Forum, 2010). [40]

Businesses tend to lack confidence in the security of cloud services and are uncertain about applicable legal issues, jurisdiction and dispute settlement mechanisms, which indicates a lack of trust overall. For small businesses, there is a clear lack of knowledge about Cloud technology, which is an impediment to adopting these cloud services. [41] Barriers concern the legal aspects of the Cloud, for example, various legal frameworks and uncertainties about applicable law, unclear jurisdiction and data location issues, complex data security and protection regulations, low trust in providers and lack of access and portability. to guaranteed data between cloud systems. [42] Cloud computing does not require the use of high-quality equipment and is easy to use. In addition, it allows the exchange of data between different platforms. [43]

Below is the economic, environmental and social impact of using Cloud technology in SCM. According to Figure 2. SCM is influenced by a multitude of elements, which lead to the transformation of classical processes with modern ones. The Cloud technology used in SCM from a social perspective has an impact on the communication between the process actors, making it more efficient (suppliers, customers, companies), but also on the way they collaborate to fulfill their work tasks. If in the traditional SCM there is no transparency and visibility on the activities / processes, through the Cloud technology, the processes can be controlled easily and quickly.

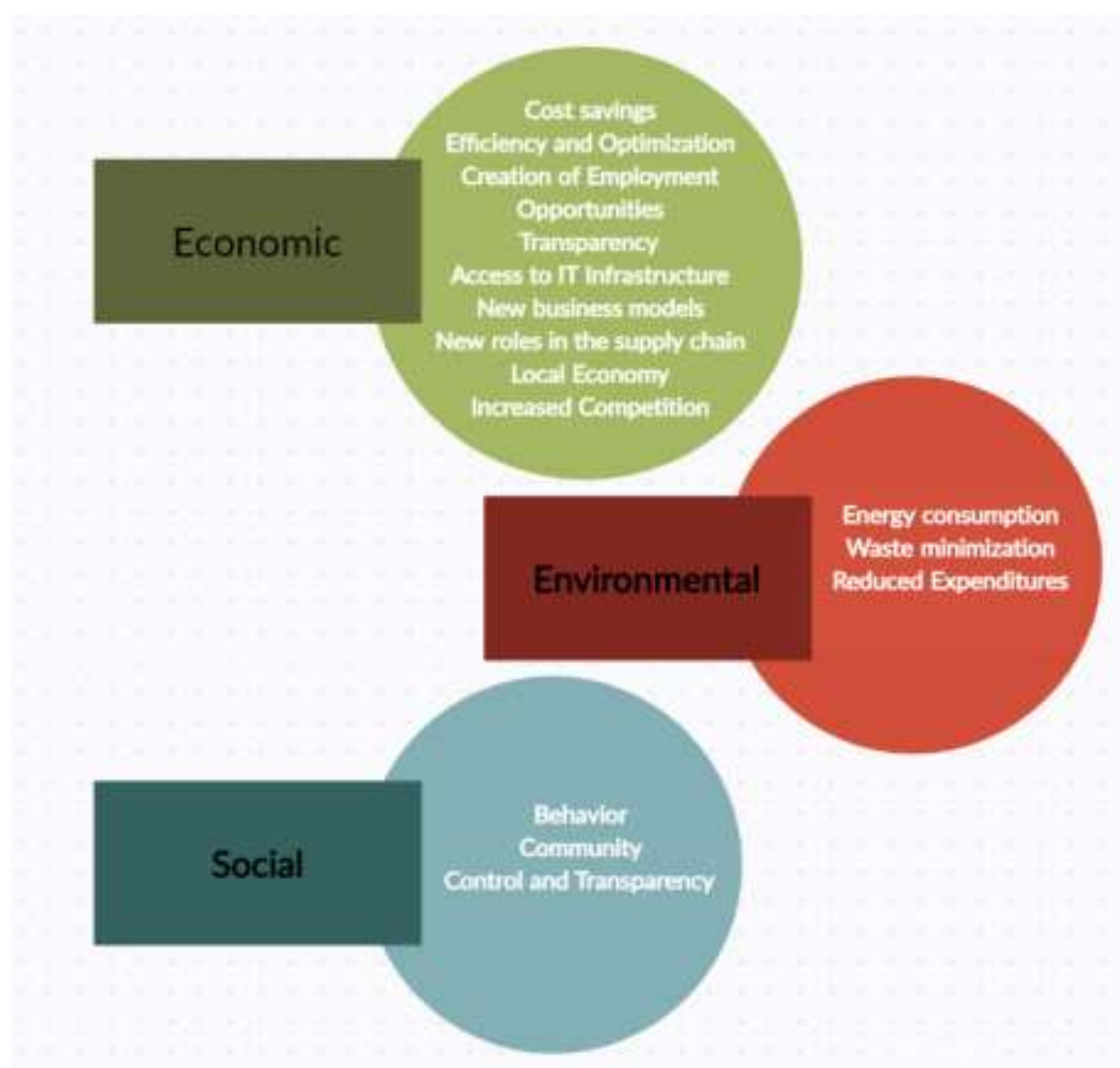

Fig. 2. The Economic, Environmental and Social Impact of using Cloud Technology

\subsection{The economic perspective}


From an economic perspective, Cloud ICT technology affects supply chain functions, making it more transparent and efficient. Cloud technology creates a more distributed supply chain, allowing the supply flow to be more circular, thus facilitating the creation of a sustainable ecosystem. Current supply chains are still mainly centralized, and holders may not yet be ready for full decentralization. In addition, Cloud improves transparency throughout the supply chain, which prevents fraud and reduces disputes between the parties. Finally, Cloud reduces administrative burdens and facilitates process automation.
Cloud has a significant impact on the sustainability of the supply chain from an economic perspective. [44] A priority for innovation in the supply chain is the economic dimension. [45]

In Figure3. are the elements that result from the economic impact of using Cloud technology in SCM: cost saving, efficiency and optimization, creating employment opportunities, transparency, access to IT infrastructure, new business models, new roles in the supply chain, local economy, increased competition.

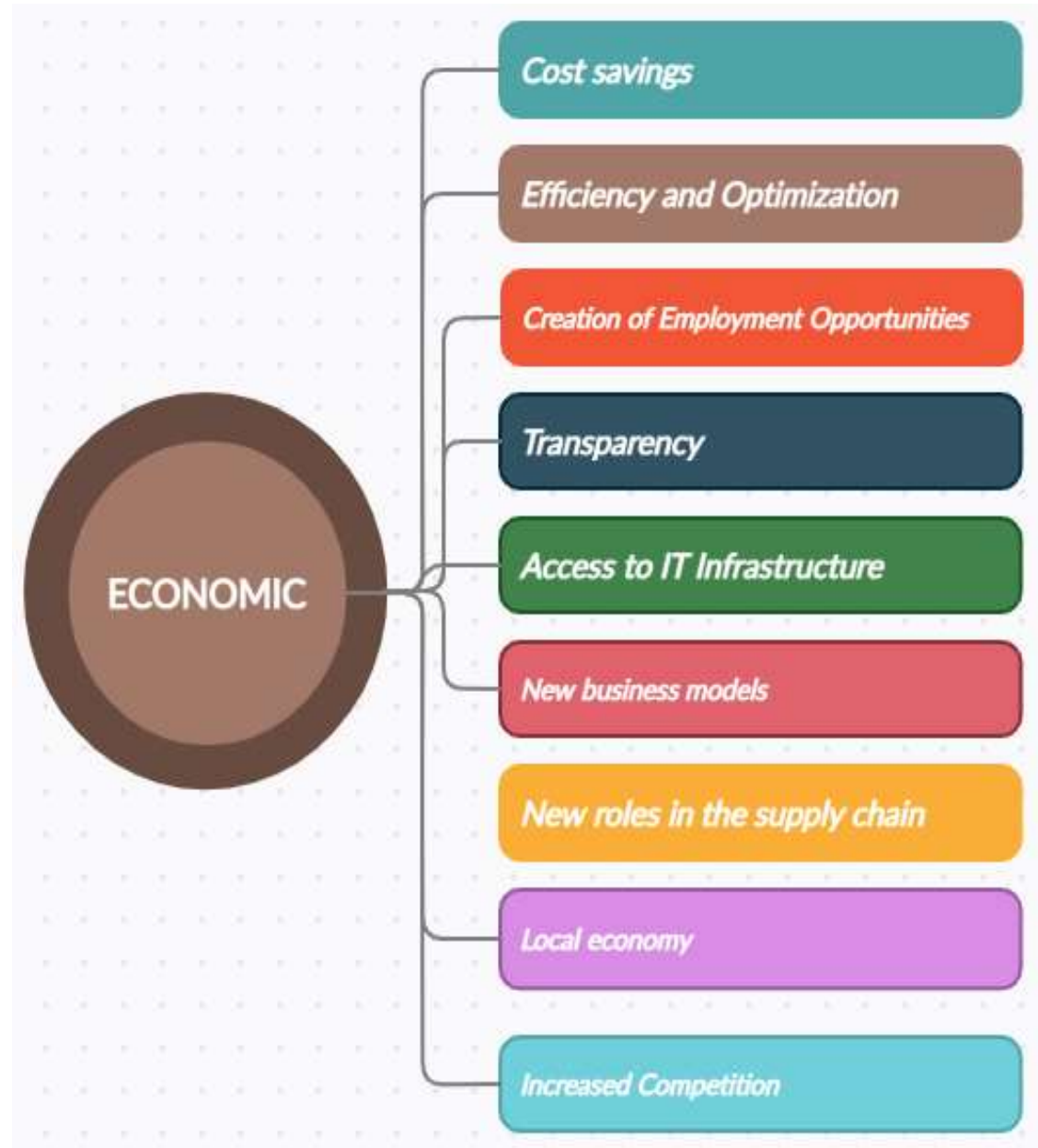

Fig. 3. The economic impact of using Cloud in SCM

\section{a. Cost savings}

Many applications of Cloud technology allow organizations to save costs, and Cloud technology leads to cost efficiency and lower market prices. Most Cloud projects focus primarily on cost-effectiveness. Many companies choose cost-effectiveness as the main engine for their projects, because it is a concept that everyone can understand and is easy to measure. Cloud technology has the potential to reduce costs for consumers, energy could be cheaper. Cloud has a positive impact on the costs of two key players in the supply chain: 
energy companies and consumers. The administrative burden of large companies is reduced and therefore reduces their costs.

When properly implemented, Cloud technology can drastically reduce IT infrastructure operations and maintenance costs.

\section{b. Efficiency and Optimization}

In general, efficiency and optimization can be improved with the help of Cloud technology. Another advantage of cloud computing is its ability to bring efficient work practices. Small businesses were the first beneficiaries of cloud computing in the sense that they explored revenue opportunities through the cloud infrastructure, streamlining overall processes, thus increasing profitability. The cloud computing infrastructure tends to be more flexible, as no initial investment is required for configuration. Companies are required to pay for server and infrastructure capacity when needed. These payments are in the form of a commission. This allows cost savings, as hardware installation costs are kept to a minimum. Moreover, this ensures efficiency without the purchase of additional equipment, installations and utilities for installation.

Cloud computing provides efficiency by using resources efficiently through scalable implementation and business agility (fast systems deployment and real-time interaction and response) [10].

\section{c. Creation of Employment Opportu- nities}

Cloud Computing ensures economic growth by offering new job opportunities. As cloud computing is used in SCM, new ways of working open up by building the data centers that are needed to host Cloud technology. Not only is it hiring additional staff to operate and maintain the systems through its data centers, but there is also a growing need to "improve" the existing workforce. This improvement also determines a higher than average salary increase. Higher wages will have a direct impact on GDP per capita as the average income of the working class increases.

\section{d. Transparency}

SCM is undergoing transformation, leveraging the power of Cloud technology for improved visibility and a stronger data analytics capability to drive decision-making. It is important that all parties in the supply chain are aware of this and choose the cloud for the right cases. A crucial question many companies ask is whether Cloud technology can create value for their business case and increase efficiency through high visibility.

\section{e. Access to IT Infrastructure}

The availability of IT resources and infrastructure is still lacking in many parts of the world. Countries that have a shortage of IT professionals and the necessary IT resources can access them through Cloud technology. This would require a reliable internet connection for accessibility. Once reliable connectivity has been established, IT resources can be used via the web, allowing for growth even in the most remote areas. This is another way to drive growth in areas where IT infrastructure may be non-existent. In cloud computing, all software can be hosted on the cloud and accessed from anywhere. Accounting software can be linked to supply chain management software via APIs. This access allows a new level of collaboration between employees, because everyone has access to the same cloud services. The use of cloud technology allows multiple platforms to work with each other through a series of standardized protocols.

\section{f. New business models}

SCM is changing and new business models are emerging, which are slowly replacing traditional models. Cloud technology stimulates the development of new business models and forces holders to re-evaluate their current business models.

Many small companies are exploring the benefits of Cloud technology to increase the speed of their simulations. By connecting to the cloud, simulations can be processed by thousands of computers simultaneously, which reduces computation time. A threeweek project can become a two-day simulation if the company uses cloud computing services to acquire ten times more processing power. Thanks to cloud technology, smaller 
companies can provide solutions as quickly as larger companies.

\section{g. New roles in the supply chain}

New business models are emerging, which means that new roles are being created for parts of the supply chain. Large SCM suppliers should not disappear in the near future, they could only play a different role in the supply chain. With the creation of new roles in the supply chain, the whole ecosystem thus becomes more and more complex.

\section{h. Local economy}

Cloud technology has the potential to stimulate local economies, support and help local small and medium-sized SCM enterprises. [47]

\section{i. Increased Competition}

Cloud computing has created innovative opportunities for small and medium-sized SCMs to use cloud technology and advance in their area of expertise. Children's industries that were initially faced with the need to find startup capital to acquire IT resources can now save on these start-up costs and innovate in the production and provision of services using rigorous research and development services. As a result, risk-neutral entrepreneurs have now entered into a level playing field as a result of higher cost savings through the use of cloud computing. As a result, competition has increased, leading to lower prices and the availability of more substitute products and services for the average consumer.

\subsection{Environmental perspective}

This subsection highlights and explains the key themes that emerged from the analysis of the environmental perspective. Cloud technology has the potential to bring more transparency to the supply chain supply function, thus creating more consumer confidence and transforming the system. Stimulates local production and reduces waste during delivery. Waste minimization influences the delivery and recycling functions of a supply chain. Some SCM processes require a lot of energy to operate, which translates into a negative impact on environmental sustainability.

Figure 4. shows three factors from an environmental perspective that result from the use of Cloud technology in SCM. The effects are waste minimization, a reduction in energy consumption and reduced costs.

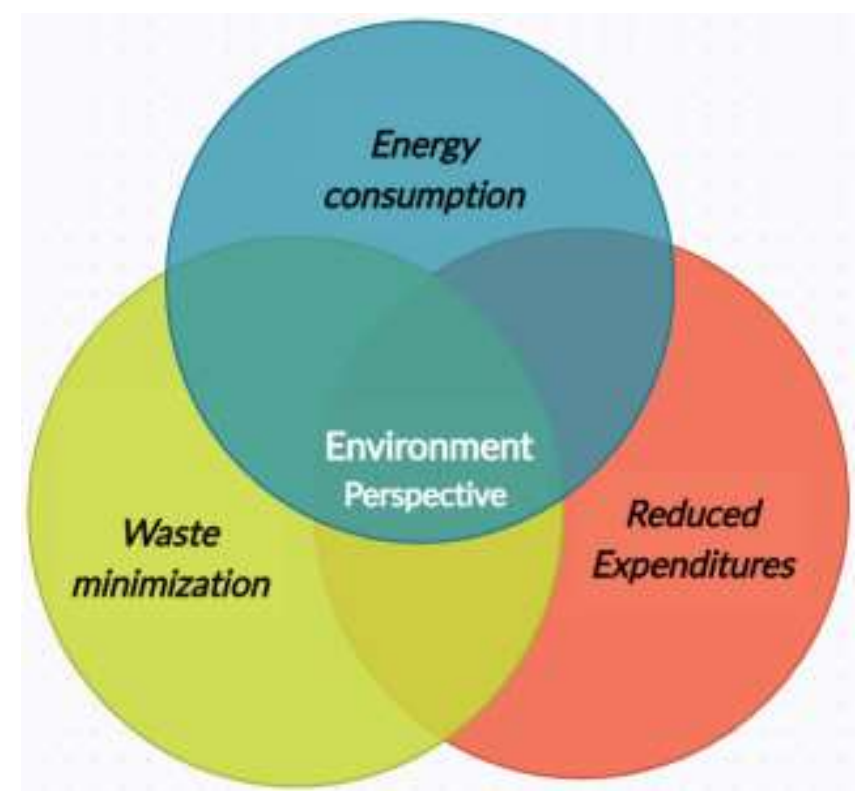

Fig. 4. Cloud in SCM - Environmental perspective

\section{a. Energy consumption}

Cloud technology is both part of the problem and part of the solution. [48] It is ambiguous how the impact of Cloud technology on sustainable development in EMS is a threat or an opportunity for the environment. [49] Compa- 
nies are looking for alternative solutions, trying to reduce their impact on the environment. Small data centers, with their independent cooling systems, will require a considerable source of energy to operate. As companies invest in cloud-based infrastructure, as they try to explore the capabilities of this platform, they discover new ways to save energy. There is a lot of "wasted energy" that needs to be maximized. For example, many computers that stay on most of the time do not maximize the energy they consume, because the machines will use more power than the period in which they will be actively used. If computers are moved to a data center, multiple servers will be replaced with a single server.

\section{b. Waste minimization}

Waste minimization is a huge environmental gain that Cloud technology can provide. Carbon emissions around the world are alarming as more and more units are investing in multiple physical resources to achieve greater achievements. The size of the company does not have to be large for investments in Cloud technology to have a huge impact. The result is the creation of efficient data centers through new technologies, which translates into a reduction in carbon emissions and the effect can be felt worldwide. Cloud technology can reduce carbon emissions by $30 \%$ for large, efficient companies and by up to $90 \%$ for the smallest and least efficient companies. [50]

\section{c. Reduced Expenditures}

Cloud computing is better at managing resources because it makes it possible to invest in what is used to run SCM operations without having to pay for the running cost of each machine. Instead of each company using its own hardware, the company shares the same hardware to increase usage, and servers are kept in air-conditioned rooms, where temperature and humidity levels are carefully maintained, and cloud providers can use efficient density plans. which are difficult to replicate for internal centers.

\subsection{Social perspective}

From a social perspective, Cloud technology mainly affects two functions of the supply chain: consumers and value proposition. Consumers need to be taken into account as much as other actors in the supply chain when implementing a new technology. End-user behavior is crucial, consumers are struggling with change and unwilling to cope with complex technology. Therefore, other actors in the supply chain can collaboratively push consumers to adopt new technologies by rewarding and educating them. Cloud technology requires party alignment, which encourages partnerships between organizations locally and globally.

Figure 5. shows three factors from a social perspective that result from the use of Cloud technology in SCM.

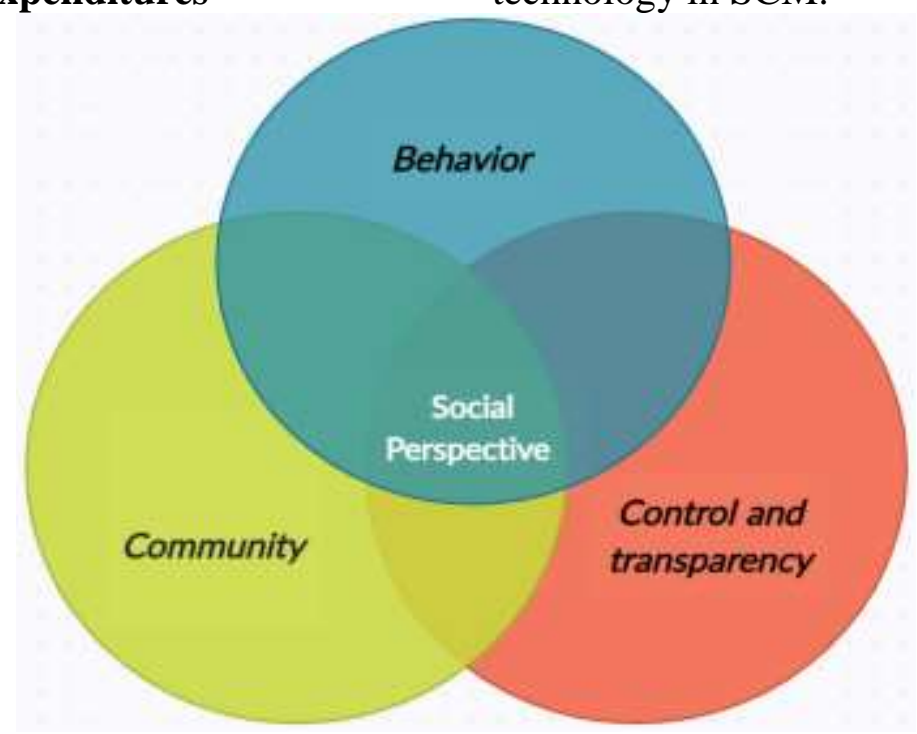

Fig. 5. Cloud in SCM - Social perspective 


\section{a. Behavior}

In addition to a technological evolution, the mentality must also change. It is important to think about a system in which users participate. [51] Users play an important role in the energy supply chain, and Cloud affects them as much as other players in the ecosystem. Several participants mentioned that users do not want to deal with complex technologies and change their habits. It is more difficult for them to understand the added value of this technology. For the implementation of Cloud technology to be successful, market rules will need to be defined, as well as the clear contribution of each party. To change users' behavior, one solution could be to stimulate and educate them.

\section{b. Community}

As a result, Cloud technology encourages consumers to help each other and stimulates collaboration. Moreover, Cloud technology encourages the creation of partnerships and synergies between companies. It not only connects businesses together, but also people with businesses (Cloud technology requires the alignment of different actors). Therefore, it becomes clear that Cloud technology brings people together and forces them to build a solution as a community. The need for collaboration can become a barrier to the implementation of cloud technology for parties with conflicting objectives. Cloud applications allow consumers to feel more involved in their local community and encourage investment in sustainable development. Cloud technology has a positive impact on their communities. Most Cloud applications require the collaboration of different parts of the supply chain, each party plays an active role, communicating and working together, the supply chain becomes more sustainable.

Cloud computing can facilitate collaboration across the entire supply chain through information processing, mobile interactivity and increased information exchange with partners. [52] [53] [54] Cloud-based procurement systems enable organizations to collaborate better and bring together multifunctional departments with mobile applications. [46]

\section{c. Control and Transparency}

Data access and portability barriers are less relevant in the short term, but are expected to become more relevant over time to all stakeholders as the intensity of cloud technology increases. Technology transparency and control barriers may diminish over time as the market matures and the interaction between SCM players becomes clearer. Concerns about controlling changes and updates to software and services should diminish over time, as companies benefit from automatic software updates at no additional cost. Also, a disadvantage of Cloud technology is the idea of the SCM organization to lose control over the data and to entrust critical information to another company. [10]

Figure 6. presents a flow of interconnected elements that show the impact of cloud technology on SCM from a social point of view. 


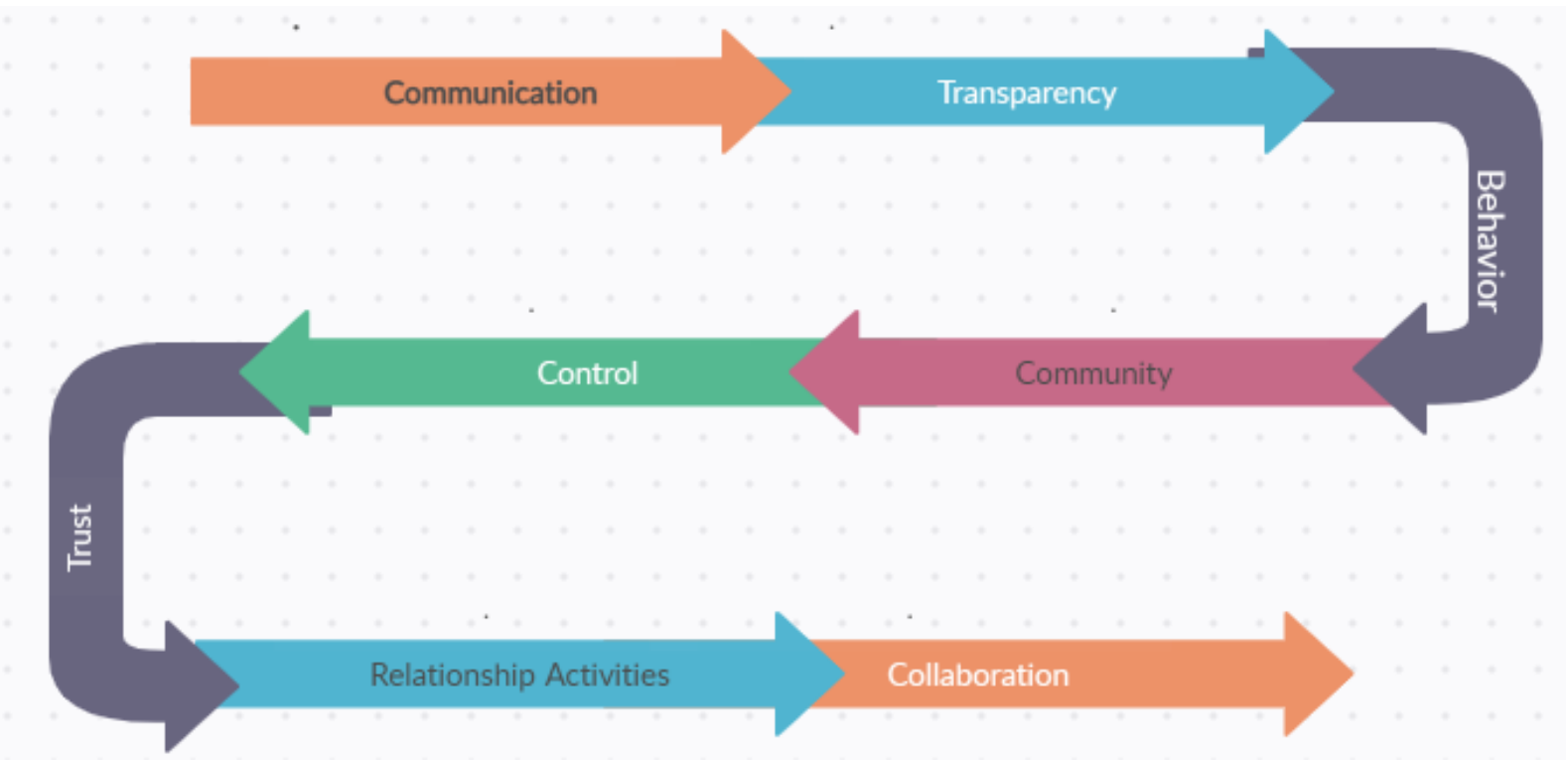

\section{Conclusions}

The results of this research indicate that information and communication technology with a focus on Cloud Computing has a positive impact on supply chain management, gradually maximizing economic profitability, minimizing environmental impact and maximizing social welfare. At the same time, this technology has disadvantages that should be taken into account when implementing these services. Taking into account all that has been discussed, cloud-based information systems are a better alternative to establish IT support for supply chain management and the resulting economic, social and environmental effects have advantages.

\section{References}

[1] D. Blanchard, Supply chain management best practices. US: John Wiley \& Sons, pp.3-273, 2010.

[2] M.M. Wilhelm, C. Blome, V. Bhakoo, and A. Paulraj, "Sustainability in multi-tier supply chains: Understanding the double agency role of the first-tier supplier,". Journal of Operations Management, 41(1), pp.42-60, 2016.

[3] C.Y. Wong, C.W. Wong, and S. Boon-Itt, "Integrating environmental management into supply chains: a systematic literature review and theoretical framework," International Journal of Physical Distribution
\& Logistics Management, 45(1/2), pp.4368, 2015.

[4] A. Genovese, A.A. Acquaye, A. Figueroa, and S.L. Koh, "Sustainable supply chain management and the transition towards a circular economy: Evidence and some applications," Omega, 66, pp.344-357, 2017.

[5] C.M. Zuppo, "Defining ICT in a Boundaryless World: The Development of a Working Hierarchy," International Journal of Managing Information Technology,4 (3), 13-22. doi:10.5121/ijmit.2012.4302, 2012.

[6] V. De Marchi, E. Di Maria, and G. Gereffi, Local clusters in global value chains: linking actors and territories through manufacturing and innovation. UK: Routledge, 2017.

[7] S. Luthra, S.K. Mangla, F.T. Chan, and V.G. Venkatesh, "Evaluating the Drivers to Information and Communication Technology for Effective Sustainability Initiatives in Supply Chains," International Journal of Information Technology \& Decision Making, 17 (01), 311-338, 2018. https://doi.org/10.1142/S0219622017500 419.

[8] L.M. Hilty, and B. Aebischer, "ICT for Sustainability: An Emerging Research Field," in Hilty L., Aebischer B. (eds) ICT Innovations for Sustainability. Advances in Intelligent Systems and Computing, vol 310. 2014, Springer, Cham. 
https://doi.org/10.1007/978-3-319-092287_1

[9] B. Grabot, and T. Schlegel, "ICT for sustainability in industry," Computers in Industry, $65 \quad$ (3), 383-385, 2014. https://doi.org/10.1016/j.compind.2014.01.016

[10] S. Marston, Z. Li, S. Bandyopadhyay, J. Zhang, and A. Ghalsasi. Cloud computing - The business perspective. Decision Support Systems, 51(1), 176-189, 2011. doi:http://dx.doi.org/10.1016/j.dss.2010.1 2.006

[11] C. Scott. Why sustainable supply chains make business sense, available at: https://www.theguardian.com/sustainable-business/sustainable-supply-chainsbusiness-sense , 2013

[12] A. Chiabai, D. Rübbelke, and L. Maurer. ICT applications in the research into environmental sustainability: a user preferences approach. Environment, Development and Sustainability, 15 (1), 2012, 81100. https://doi.org/10.1007/s10668-0129376-2

[13] A. Thöni, and A. Tjoa, Information technology for sustainable supply chain management: a literature survey, Enterprise Information Systems, VOL. 11, NO. 6, 2017 , 828-858 http://dx.doi.org/10.1080/17517575.2015. 1091950

[14] J, Llach, and M.D. Alonso-Almeida. Integrating ICTs and Supply Chain Management: The Case of Micro-Sized Firms. Human Factors and Ergonomics in Manufacturing \& Service Industries, 25 (4), 2014, 385-397. https://doi.org/10.1002/hfm.20559

[15] X. Zhang, D. Pieter van Donk, and T. van der Vaart, Does ICT influence supply chain management and performance? A review of survey-based research, International Journal of Operations \& Production Management, Vol. 31 Issue: 11, 2011, pp.1215-1247, https://doi.org/10.1108/01443571111178 501
[16] D. Pieter van Donk, Challenges in relating supply chain management and information and communication technology: An introduction, International Journal of Operations \& Production Management, Vol. 28 Issue: 4, pp.308-312, 2008, https://doi.org/10.1108/01443570810861 534

[17] S. Culp, Supply Chain Disruption A Major Threat to Business. Retrieved March 16, 2018, from https://www.forbes.com/sites/steveculp/2013/02/15/supply-chain-disruption-a-major-threat-to-business/

[18] H. Yu, A.Z. Zeng, and L. Zhao. Single or dual sourcing: Decision-making in the presence of supply chain disruption risks. Omega,37 (4), 788-800, 2009. https://doi.org/10.1016/j.omega.2008.05. 006

[19] L.M. Ellram, and M.C. Cooper, Supply chain management: it is all about the journey, not the destination, Journal of Supply Chain Management, Volume 50, Number $1,2014$.

[20] P. Zhang, S. Aikman, and H. Sun, Two Types of Attitudes in ICT Acceptance and Use, Intl. Journal of Human-Computer Interaction, 24:7, 628-648, 2008, https://doi.org/10.1080/10447310802335 482

[21] C.M. Zuppo. Defining ICT in a Boundaryless World: The Development of a Working Hierarchy. International Journal of Managing Information Technology, 4 (3), 13-22, 2012. doi:10.5121/ijmit.2012.4302

[22] M. Pagell, and A. Shevchenko. Why research in sustainable supply chain management should have no future. Journal of Supply Chain Management, 50(1), 44-55, 2014.

[23] J. Meehan, and D. Bryde. Sustainable Procurement Practice. Business Strategy and the Environment, 20, 94-106, 2011.

[24] M. Nurunnabi. Tensions between politico-institutional accounting regulation in a developing economy: insights from institutional theory. Business Ethics: A European Review, 24(4), 398 - 424, 2015. 
[25] V. Vracheva, and R. Mason. Creating Firm Value through Stakeholder Management and Regulation. Journal of Managerial Issues, XXVII(1- 4), 120-140, 2015.

[26] I. Yüksel. Developing a Multi-Criteria Decision-Making Model for PESTEL Analysis. International Journal of Business and Management, 7(24), 52-66, 2012.

[27] M. Christopher. Logistics \& supply chain management. UK: Pearson, 2016.

[28] Y. Wang, V. Sanchez Rodrigues, and L. Evans. 'The use of ICT in road freight transport for $\mathrm{CO} 2$ reduction-an exploratory study of UK's grocery retail industry'. The International Journal of Logistics Management, 26(1), pp.2-29, 2015.

[29] M.I.I. Tan, R.N. Razali, and M.I. Desa, "Factors influencing ICT adoption in halal transportations: A case study of Malaysian halal logistics service providers," International Journal of Computer Science Issues (IJCSI), 9(1), p.62, 2012.

[30] O. Oyebiyi, S. Misra, R. Maskeliūnas, and R. Damaševičius, R. 'Application of ICT by Small and Medium Enterprises in Ogun State Nigeria'. In International Conference on Recent Developments in Science, Engineering and Technology, 4(2), pp. 459-471, 2017.

[31] A. Majchrzak, M.L. Markus, and J. Wareham. 'Designing for digital transformation: Lessons for information systems research from the study of ICT and societal challenges. MIS Quarterly, 40(2), pp.267-277, 2016.

[32] V. De Marchi, E. Di Maria, and G. Gereffi. Local clusters in global value chains: linking actors and territories through manufacturing and innovation. UK: Routledge, 2017.

[33] F. Etro. "The economic impact of cloud computing on business creation, employment and output in Europe," Review of Business and Economics, 54, 2 2009), 179-208

[34] Centre for economics and business research ltd THE CLOUD DIVIDEND: Part One. The economic benefits of cloud computing to business and the wider EMEA
economy-France, Germany, Italy, Spain and the UK (December 2010 2010), 89

[35] Centre for economics and business research ltd THE CLOUD DIVIDEND: Part Two The economic benefits of cloud computing to business and the wider EMEA economy. Comparative analysis of the impact on aggregated industry sectors2011)

[36] B. Martens, M. Walterbusch, and F. Teuteberg, Costing of cloud computing services: A total cost of ownership approach. IEEE, 2012.

[37] H. Schrödl, and K. Turowski. SCOR in the cloud - Potential of cloud computing for the optimization of supply chain management systems. In Proceedings of the European, Mediterranean \& Middle Eastern Conference on Information Systems. Athens, Greece: IEEE, 2011.

[38] T. Schramm, S. Nogueira, and D. Jones. Cloud computing and supply chain: A natural fit for the future. Logistics Management. Retrieved September 14, 2012, from http://www.logisticsmgmt.com/

[39] Supply Chain Digital, available at: https://www.supplychaindigital.com/technology/how-luxury-retailers-are-usingblockchain-tackle-counterfeits-supplychain

[40] World Economic Forum, 2010. Exploring the Future of Cloud Computing: Riding the Next Wave of TechnologyDriven Transformation. [online]. Available at: https://dev1.oerafrica.org/system/files/9060/wef-exploring-futurecloud-computing_0.pdf?file $=1 \&$ type $=$ node $\&$ id $=9060 \&$ force

[41] Fact and figures about the EU's Small and Medium Enterprise (SME). See: http://ec.europa.eu/enterprise/policies/sme/factsfigures-analysis/index_en.htm

[42] OECD, Cloud computing: The Concept, Impacts and the Role of Government Policy, 2014

[43] S. Zhang, S. Zhang, X. Chen, X. Huo, S. Cloud computing research and development trend. In: Second International Conference on Future Networks, (ICFN '10), 
January 22-24, 2010, Sanya, China, pp. 93-97

[44] M. Charbonnier. The impact of information and communication technology (ICT) on supply chain sustainability. The case of the blockchain in the energy industry, University of Amsterdam, 2018.

[45] D. Gao, Z. Xu, Y.Z. Ruan, and H. Lu. From a systematic literature review to integrated definition for sustainable supply chain innovation (SSCI). Journal of Cleaner Production, 142, 2017, 15181538. doi:10.1016/j.jclepro.2016.11.153

[46] M. Koploy. 2011 Market Trends Report: Procurement Retrieved October 9, 2013, from http://blog.softwareadvice.com/articles/scm/2011-market-trends-report-procurementsystems-1030711/

[47] P. Bock. The blockchain could give a big boost to local economies, 2016. , available at: https://www.wired.co.uk/article/colublockchain-local-economies-wiredmoney-2016

[48] B. Grabot, and T. Schlegel. ICT for sustainability in industry. Computers in Industry,65 (3), 383-385, 2014. doi:10.1016/j.compind.2014.01.016

[49] A. Chiabai, D. Rübbelke, and L. Maurer. ICT applications in the research into environmental sustainability: a user prefer- ences approach. Environment, Development and Sustainability,15 (1), 81-100, 2012. doi:10.1007/s10668-012-9376-2

[50] Cloud computing and the Sustainability: The Environmental Benefit of moving to the cloud (2010), Accenture, WSP and Microsoft and http://www.scientificamerican.com/article/cloud-computing-savesenergy

[51] E. Venkina. Blockchain in the energy transition: Hope or hype?|DW, 2018. Retrieved from https://www.dw.com/en/blockchain-inthe-energy-transition-hope-or-hype/a43025756

[52] A. Benlian, and T. Hess. Opportunities and risks of software-as-a-service: Findings from a survey of IT executives. Decision Support Systems, 52(1), 232-246, 2011.

[53] B. Iyer, and J.C. Henderson. Preparing for the future: understanding the seven capabilities of cloud compu-ting. MIS Quarterly Executive, 9(2), 117-131, 2010.

[54] A. Parmigiani, R.D. Klassen, and M.V. Russo. Efficiency meets accountability: Performance implications of supply chain configuration, control, and capabilities. Journal of Operations Management, 29(3), 212-223, 2011.

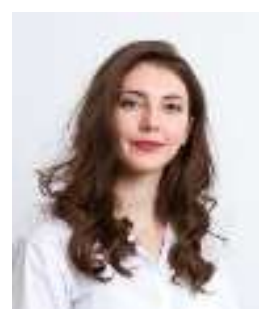

Elena Puică, student at Economic Informatics Doctoral School, The Bucharest University of Economic Studies since 2020, working as a professional SAP Consultant. 